\title{
Desafios da agricultura familiar em prol da produção agroecológica em Tangará da Serra/MT
}

A produção agroecológica vem ao longo dos anos ganhando espaço nas pequenas propriedades. Tal fato se dá pelos diversos incentivos ocorridos em âmbito regional, estadual e nacional. Em âmbito regional, a Secretaria da Agricultura Pecuária e Abastecimento do município de Tangará da Serra (SEAPA) desenvolveram um projeto de Produção Agroecológica Integrada e Sustentável em uma unidade experimental e desejava testá-lo nas propriedades rurais locais. Em contrapartida um grupo de dez produtores da comunidade rural Vale do Sol I requereram junto a SEAPA um apoio para produzirem de forma diferenciada e aumentar a renda familiar. O objetivo da pesquisa consistiu em identificar os desafios a serem superados pelos produtores da comunidade rural Vale do Sol I em prol da produção agroecológica. Trata-se de uma pesquisa qualitativa com o apoio de entrevistas aplicada aos profissionais técnicos da SEAPA e aos produtores rurais. Como resultados, foi possível conhecer o sistema de produção vigente, os recursos físicos e monetários disponíveis, bem como a infraestrutura das unidades produtivas A pesquisa sinaliza que a principal motivação dos produtores rurais à produção agroecológica consiste na busca do diferencial competitivo, com o lançamento de uma nova marca no mercado. Para iniciarem as atividades de mudanças no sistema de produção convencional para o agroecológico buscaram apoio e orientação junto aos técnicos agrícolas da prefeitura municipal, ao representante do Núcleo de Políticas para Economia solidária e professores universitários. A falta de água e do documento das terras são os principais empecilhos para captação de recursos para os investimentos necessários. Foram identificadas manifestações do trabalho coletivo, como alternativa para superar dificuldades de transporte e comercialização, embora a produção ainda ser individualizada. Apesar das dificuldades identificadas, conclui-se ser possível aos pequenos agricultores produzir de forma integrada e sustentável desde que sejam feitas as adequações recomendadas nas propriedades e que o trabalho coletivo seja formalizado em associação ou cooperativa. Como pesquisas futuras sugere-se que sejam realizados outros estudos na mesma comunidade a fim de verificar as adequações ocorridas nas propriedades bem como a aceitação do mercado local para o consumo de produtos agroecológico.

Palavras-chave: Motivações; Cultivo; Sustentabilidade.

\section{Challenges of family agriculture in support of the agroecological production in Tangará da Serra/MT}

\begin{abstract}
Over the years, the agroecological production has been gaining ground in small properties. This fact is given by the various incentives occurring in regional, state and national level. Regionally, the livestock agriculture and supply department of the town Tangara da Serra (SEAPA) have developed a Integrated Agroecology Production project and Sustainable in an experimental unit and wanted to test it in local farms. On the other hand a group of ten producers in the rural community Vale do Sol I applied with SEAPA a support to produce differently and increase family income. The goal of the research was to identify the challenges to be overcome by the producers in the rural community Vale do Sol I in favor of agro-ecological production. This is a qualitative research with the support of interviews applied to technical professionals of SEAPA and farmers. As a result, it was possible to know the current production system, the physical and monetary resources available, as well as the infrastructure of production units. The survey indicates that the main motivation of farmers to the agro-ecological production is in search of competitive advantage, with the launch of a new brand. To initiate the activities of changes in the conventional production system for agroecological, it was sought support and guidance from the agricultural technicians of the city hall, the representative Policy Center for Economic solidarity and professors. The lack of water and the paper of the land are the main stumbling blocks to raising funds for the necessary investments. Collective work demonstrations have been identified as an alternative to overcome difficulties of transportation and marketing, while production still has been individualized. Despite the indentified difficulties, it is concluded to be possible for small farmers to produce an integrated and sustainable manner provided since it is made the adjustments recommended in the properties and the collective work is formalized in association or cooperative. As further research, it is suggested to be done other studies in the same community in order to check the adjustments that occurred in the properties and the acceptance of the local market for the consumption of agro-ecological products.

Keywords: Motivation; Cultivation; Sustainability.
\end{abstract}

Topic: Química Agrícola e Ambiental

Reviewed anonymously in the process of blind peer

Regina Maria da Costa

Universidade do Estado de Mato Grosso, Brasil

http://lattes.cnpq.br/2865351259938143

regina.m.costa@unemat.br

Aparecida de Fátima Alves Lima

Universidade do Estado de Mato Grosso, Brasil

http://lattes.cnpq.br/4060958369478360

afal.lima@gmail.com

Q

DOI: 10.6008/SPC2179-6858.2017.001.0018
Received: 20/04/2016

Approved: 22/05/2016
Referencing this:

COSTA, R. M.; LIMA, A. F. A.. Desafios da agricultura familiar em pro da produção agroecológica em Tangará da Serra/MT. Revista IberoAmericana de Ciências Ambientais, v.8, n.1, p.208-217, 2017. DOI: http://doi.org/10.6008/SPC2179-6858.2017.001.0018 


\section{INTRODUÇÃO}

A agricultura familiar desempenha importante papel na agricultura brasileira, pela sua diversificação de culturas, o que a torna fornecedora de grande parte dos alimentos consumidos. Apoiados em Schneider (2003) verificamos que a expressão "agricultura familiar" vem ganhando legitimidade social e científica no Brasil, passando a ser utilizada com frequência nos discursos dos movimentos sociais do meio rural e por instituições governamentais. Segundo Souza Filho e Batalha (2005) o desempenho dos empreendimentos caracterizados como agricultura familiar é determinado por um conjunto grande de motivações, decorrentes das políticas públicas e da conjuntura macroeconômica, local ou regional.

Dentre as diversas motivações políticas existentes, a que convém citar por hora é o contexto da Revolução Verde que ocorreu durante as décadas de 1960 a 1970, período este em que a agricultura familiar foi ignorada. Os defensores da ideia da Revolução Verde apoiavam um modelo de produção expansivo, por acreditar que a produção em grande escala salvaria a crise do abastecimento de alimentos que o mundo vivenciava. O fato é que em nome da bandeira das inovações tecnológicas, não houve preocupação com os danos ambientais, comprometendo florestas, o solo e a água.

Em contrapartida, a agricultura familiar se manteve limitada a uma produção de pequeno porte buscando se adequar ao cultivo mais consciente com respeito aos recursos naturais. Nas palavras de Wilkinson (2004, p.82) mesmo no clima altamente desfavorável, por estar competindo com a produção em grande escala, muitos grupos de pequenos produtores investiam em inovações organizacionais e tecnológicas, objetivando manter a biodiversidade e a sustentabilidade produtiva, por meio da pequena produção.

Dentre as inovações organizacionais e tecnológicas que visa à sustentabilidade do agroecossistema em propriedades rurais e familiares a produção agroecológica é uma das alternativas, pois se caracteriza pela aplicação de conceitos e princípios ecológicos (GLIESSMAN, 2001).

A agroecologia resulta de duas ciências, sendo elas a agronomia e a ecologia. A ecologia preocupase com estudos de sistemas naturais enquanto a agronomia aplica métodos de investigação científica à prática da agricultura. De um lado uma ciência pura e a natureza e de outro lado à ciência aplicada ao esforço humano, mantendo relativamente separado as duas disciplinas (GLIESSMAN, 2001).

Em relação às ações práticas desenvolvidas pelo esforço humano no sentido de promover o cultivo agroecológico, temos como exemplo os encontros Estaduais de Agroecologia e Feira de Roças e Quintais que ocorrem desde 2011, em Cuiabá, capital do Estado. É relevante destacar também os encontros regionais de agricultores familiares que se dedicam à agroecologia.

Nos encontros regionais e estaduais, os produtores rurais, apresentam suas experiências com a produção agroecológica, bem como, as diretrizes das políticas vigentes de agroecologia. Um dos objetivos é demonstrar para a sociedade que é possível produzir alimentos com maior qualidade, com respeito ao meio ambiente e à cultura alimentar regional. 
Portanto, é num cenário de pequenas propriedades rurais familiares, com o interesse pela produção agroecológica é que se desenvolveu a presente pesquisa. Em 2011 técnicos da Secretaria da Agricultura Pecuária e Abastecimento do município de Tangará da Serra - MT (SEAPA) desenvolveram na unidade experimental da Escola Agrícola Ulisses Guimarães, um programa de cultivo Agroecológico Integrado e Sustentável (PAS) que serviriam como base para a replicação nas propriedades rurais que apresentassem interesse.

O programa de cultivo municipal teve como referencia o programa de Produção Agroecológica Integrada e Sustentável (PAIS) conforme figura 1. É uma iniciativa do Serviço Brasileiro de Apoio as Micro e Pequenas empresas (SEBRAE nacional), porém, o programa municipal adaptado, oferecia um diferencial "a produção do frango agroecológico" ${ }^{1}$, além da diversidade de verduras, legumes e frutas que este sistema proporciona.

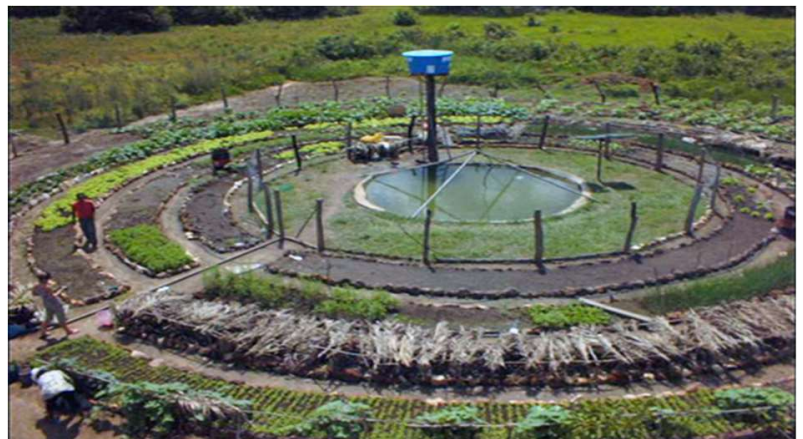

Figura 1: Cultivo de horta em forma de Mandala, modelo projeto PAIS. Fonte: SEBRAE (2008).

Após testar a viabilidade técnica e financeira do programa PAS na unidade experimental, os resultados obtidos foram satisfatórios, confirmando a possibilidade de o pequeno produtor produzir alimentos diversificados, mais saudáveis e de baixo custo.

No final do mesmo ano (2011), surge na SEAPA à demanda de um grupo de produtores da comunidade rural Vale do Sol I, requerendo orientações para aumentar a renda familiar e obter um diferencial na comercialização dos produtos que produziam.

Nesse contexto, a SEAPA, o Núcleo de Políticas para Economia Solidária (NUPES) e a Universidade do Estado do Mato Grosso (UNEMAT) se uniram para atender essa demanda e apresentaram aos produtores a proposta do PAS.

A proposta foi aceita pelos produtores e em 2012 deu-se início às ações do projeto, que consistiu em três etapas: (I) Sensibilização dos produtores; (II) Incorporação de novas práticas; (III) Adequação das unidades produtivas.

\footnotetext{
${ }^{1}$ A ideia do produto frango agroecológico é um resultado do projeto PAS (Produção Agroecológica Integrada e Sustentável) que surgiu de uma adaptação do programa PAIS do SEBRAE Nacional, pelos técnicos da Secretaria Municipal de Agricultura, Pecuária e Abastecimento (SEAPA). Visava à integração da produção sustentável e a agricultura familiar para a geração de renda de produtores rurais familiares do Município de Tangará da Serra (SILVA e CALEMA, 2012, p.8 citado por o SEBRAE, 2009, p. 6). Faziam parte desse projeto a SEAPA e o NUPES, alguns profissionais da Universidade do Estado do Mato Grosso (UNEMAT) participaram como parceiros.
} 
$\mathrm{Na}$ fase de sensibilização foram realizadas reuniões mensais com homens, jovens e mulheres e a disseminação de práticas econômicas e ecologicamente sustentáveis. Na fase de incorporação de novas práticas foram disponibilizadas informações sobre práticas agroecológicas no dia-a-dia e o suporte para a implantação de uma horta sem a utilização de produtos químicos, agrotóxicos e adubos altamente solúveis. $\mathrm{Na}$ terceira fase os produtores deveriam adequar a infraestrutura das unidades produtivas nos requisitos essenciais, água, mecanismos para irrigação e energia. Nessa fase ainda foram oferecidas oficinas que discutiam as temáticas "organização do trabalho, associativismo e cooperativismo".

Durante as visitas a campo e acompanhamento das ações do projeto foi possível concretizar esse estudo. O objetivo consistiu em identificar os desafios a serem superados pelos produtores da comunidade rural Vale do Sol I em prol da produção agroecológica.

Sabe-se que o processo de transição do sistema de produção convencional para o agroecológico é caracterizado por diversas formas de manejo de agrossistemas, mas também consideram dimensões, sociais, culturais, econômicos e ambientais, entre outras (CAPORAL e COSTABEBER, 2010). Estas múltiplas dimensões dependem da sensibilização dos agentes produtivos e por isso as mudanças de atitudes dos produtores rurais familiares estão inter-relacionadas aos desafios a serem superados para a produção agroecológica.

\section{METODOLOGIA}

A pesquisa foi realizada durante o ano de 2012, na comunidade rural Vale do Sol I, criada desde 2006, com recursos do Programa Nacional de Crédito Fundiário (PNCF), composta por 88 unidades produtivas, com aproximadamente, quatro hectares cada. Está localizada a $10 \mathrm{~km}$ do perímetro urbano do município de Tangará da Serra MT, cuja estrutura fundiária é notada de pequenas propriedades rurais. Ao todo, são 1.484 estabelecimentos rurais no município, sendo que em torno de $80 \%$ destes pertencem a agricultores familiares.

Para a coleta de dados, foram elaborados dois roteiros semiestruturados de entrevistas: um direcionado para 10 (dez) produtores da comunidade Vale do Sol I, que faziam parte do projeto PAS, que objetivava a criação do "Frango agroecológico".

Um roteiro teve a finalidade de identificar o sistema de produção vigente, os recursos físicos e monetários disponíveis, bem como a infraestrutura das unidades produtivas. Buscou-se também conhecer as motivações e desafios que levaram os produtores rurais a optar pelo sistema de produção agroecológico. O outro roteiro de entrevista foi direcionado aos profissionais da Secretaria Municipal de Agricultura (SEAPA), o que permitiu identificar as ações práticas de apoio oferecidas aos agricultores familiares.

A entrevista é um instrumento da pesquisa qualitativa, definida como uma técnica em que o investigador se apresenta frente ao investigado e lhe coloca perguntas, com o objetivo de obtenção dos dados que interessam a investigação. Dessa maneira é uma fórmula de diálogo assimétrico, em que uma das partes busca coletar dados e a outra se apresenta como fonte de informação (GIL, 2002).

Outra técnica para a coleta dos dados foi às visitas a campo e acompanhamento das ações do projeto que foram estruturadas em três fases: a primeira, cujo objetivo era a sensibilização dos pequenos agricultores 
com a realização de reuniões mensais nas unidades produtivas, seminários incluindo jovens e mulheres, e outras formas de interação para disseminar práticas econômica e ecologicamente sustentáveis.

$\mathrm{Na}$ segunda fase do projeto, o objetivo era a incorporação dos conhecimentos e práticas agroecológicas no dia-a-dia dos agricultores, com a implantação de uma horta sem a utilização de produtos químicos, agrotóxicos e adubos altamente solúveis. Para a terceira e última fase do projeto, estava previsto a adequação das unidades produtivas principalmente, quanto à disponibilidade de água para irrigação.

\section{RESULTADOS}

Ao verificar o sistema de produção vigente na Comunidade Vale do Sol I, constatou-se que apesar da participação de 10 agricultores familiares no projeto "frango agroecológico", o sistema predominante era o convencional e com o uso de produtos químicos principalmente, no cultivo das hortaliças. Do total de 88 unidades produtivas, apenas $11 \%$ adotavam práticas com base ecológica, tais como: a produção de composto orgânico e cultivo de uma horta agroecológica, com isso estariam transformando o sistema convencional em agroecológico, pois os frangos deveriam se alimentar de verduras produzidas de forma orgânica.

Em relação aos recursos físicos e monetários disponíveis, entre os agricultores entrevistados, a maioria (90\%) relataram dificuldades relacionadas com falta de mão de obra familiar. A maioria das propriedades (60\%), contam apenas com a presença do patriarca, esposa e filhos pequenos, uma vez que os jovens se deslocam para a cidade em busca de estudo e voltam para casa apenas nos finais de semana. Constatou-se neste grupo de produtores rurais, a disposição para ajuda mútua com troca de dias para o trabalho.

Quanto aos recursos humanos externos, a SEAPA colocou à disposição dos produtores, orientações técnicas de engenheiro Agrônomo, médico Veterinário e Técnicos Agrícolas. As ações proporcionadas pelos profissionais da UNEMAT foram orientações quanto à importância da organização do trabalho, cooperativismo e associativismo, através de oficinas nas reuniões mensais. Já a coordenação do NUPES repassou informações sobre Economia Solidária e Empreendimentos Coletivos.

Em relação aos recursos financeiros $70 \%$ dos agricultores familiares não possuíam o mínimo necessário para investir nas adequações das propriedades conforme previa o projeto. Verificou-se que $30 \%$ deles não reuniam condições para acesso ao crédito junto aos bancos oficiais, como por exemplo, falta do Documento de Aptidão (DAP) para ingresso ao Programa Nacional de Crédito Fundiário (PNCF).

Por outro lado, em entrevista com os profissionais da SEAPA, foi informado que os implementos agrícolas necessários, poderiam ser fornecidos, pela Secretaria municipal, em forma de empréstimo, além do suporte técnico nas adaptações necessárias dentro das propriedades.

No que tange às adequações da infraestrutura das unidades produtivas a serem implementadas, existiam alguns desafios que deveriam ser superados, como exemplo a falta de água, para irrigação das culturas. Os produtores optaram pela construção de poço comum, mas, nem todos tiveram sucesso.

A Associação da comunidade adaptou dois poços semi-artesiano com o intuito de resolver o problema da escassez de água. Os produtores teriam que dividir o custo da energia consumida pelas bombas, 
mas os custos com a instalação dos canos para levar água a cada propriedade seria individual. No entanto, no decorrer do tempo, alguns produtores locais começaram a não cumprir com suas obrigações tornando embaraçosa a solução deste problema. As mudanças exigidas nas propriedades tinham como referência o projeto PAS que estavam instalados na unidade experimental da SEAPA, conforme ilustrações:

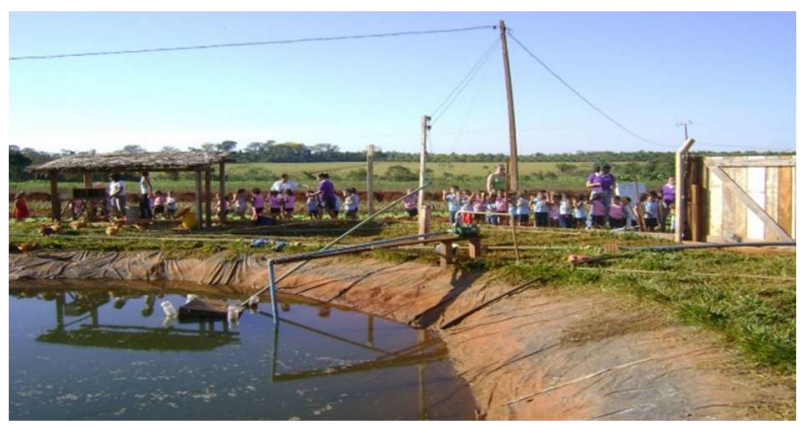

Figura 2: Tanque para irrigação e criação de peixes no projeto PAS em Tangará da Serra - MT. Fonte: SEAPA (2012)
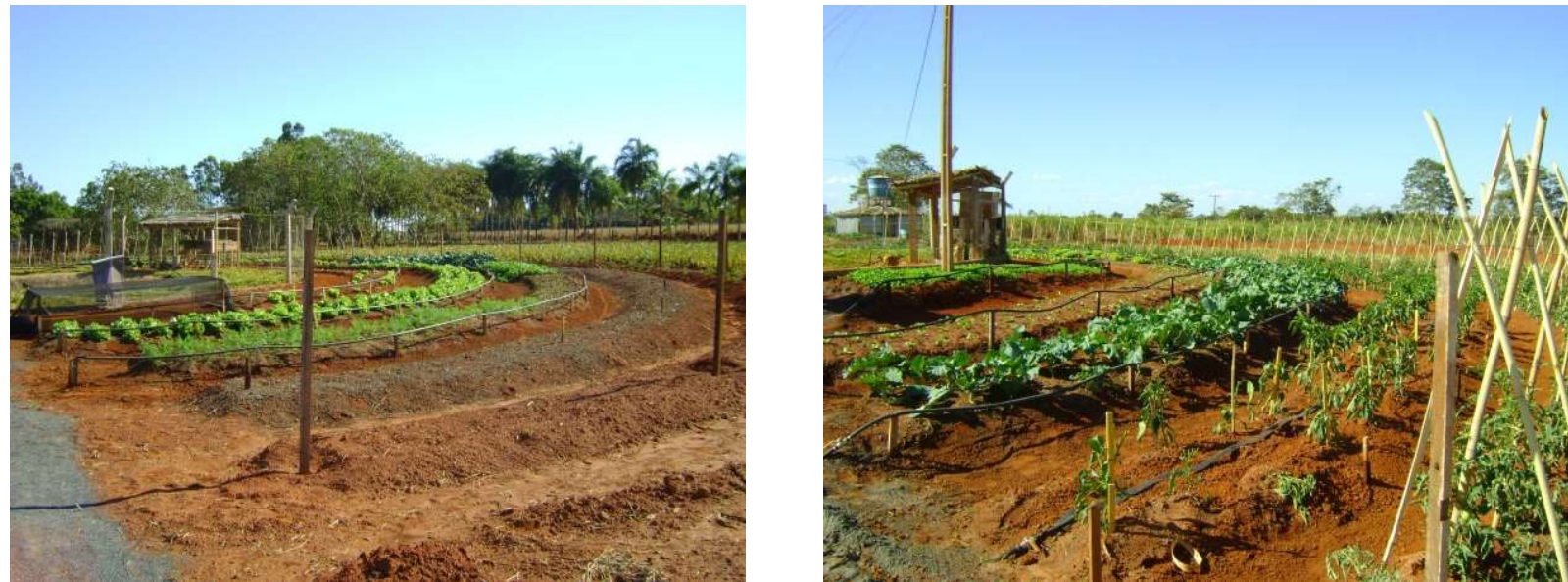

Figura 3a e 3b: Produção de hortaliças orgânicas no Projeto PAS em Tangará da Serra - MT. Fonte: SEAPA (2012).
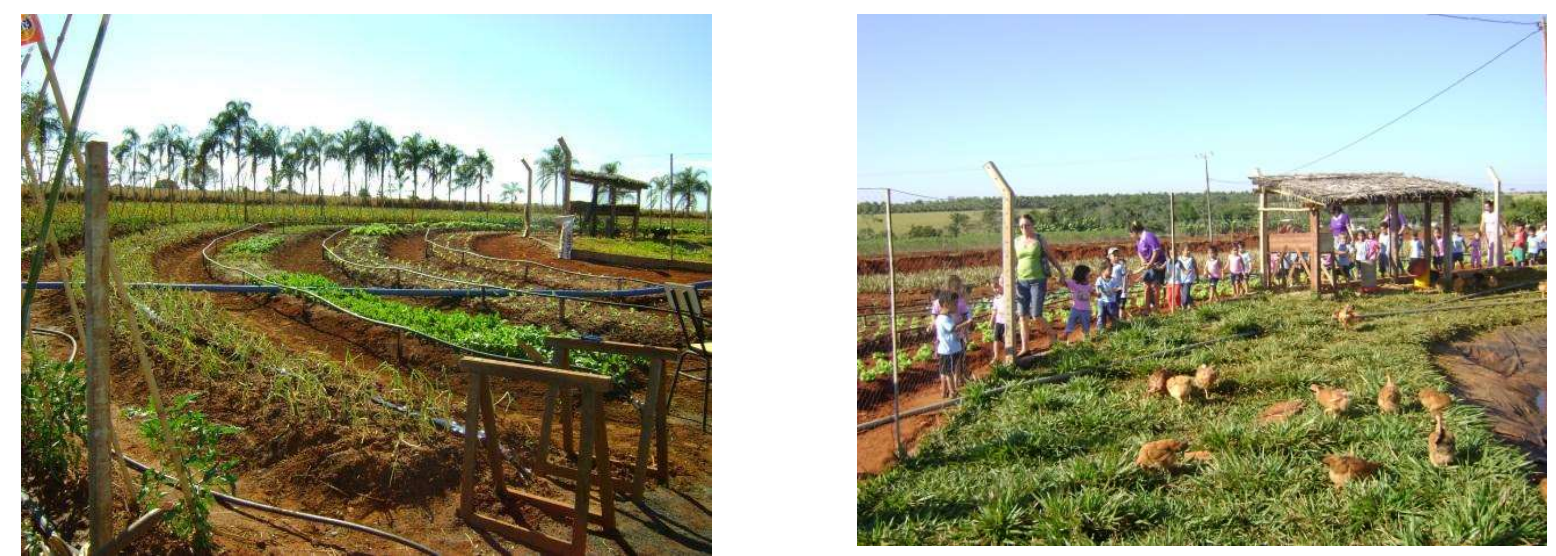

Figura 4a e 4b: Produção de hortaliças e frango agroecológico no Projeto PAS em Tangará da Serra - MT. Fonte: SEAPA (2012).

Ao analisar o custo financeiro para implantar o sustento de produção do projeto PAS, adaptado pelo SEAPA concluiu ser esta uma alternativa viável ao pequeno produtor, uma vez que o investimento projetado em 2012 seria de R\$ 4.559,65 (Quatro mil quinhentos e cinquenta e nove reais e sessenta e cinco centavos). Podendo ser cultivados diversos tipos de alimentos, garantindo assim o sustento da família, aproveitando as sobras para a alimentação dos animais e ainda obter renda com a comercialização dos excedentes. 
A perspectiva por parte dos produtores da comunidade Vale do Sol I era desafiante, pois os anseios do grupo vinham ao encontro com os objetivos do projeto PAS. A Secretaria Municipal de Agricultura tinha a necessidade de concretizar o projeto citado e com a demanda dos produtores estariam colocando em execução uma proposta e conformidade com os objetivos deles.

Apesar dos desafios a serem superados, os produtores demonstravam motivações para a concretização do projeto. Na fase das reuniões de sensibilização que ocorriam mensalmente, pode-se identificar que os mesmos, compreendiam a necessidade de mudanças no sistema convencional. Visualizava na produção agroecológica, uma oportunidade para aumentar a renda e o sustento da família, por meio da comercialização de alimentos mais saudáveis, como frutas, hortaliças e o frango caipira. Além destes motivadores também estavam presentes na decisão de mudança os fatores: qualidade de vida, sustentabilidade ambiental, preocupação com a saúde pessoal e familiar e a criação de uma nova marca no mercado.

Referente ao fator qualidade de vida, os produtores almejavam um estilo de vida diferente, consciente e preocupado com o cultivo de alimentos saudáveis. A sustentabilidade ambiental também foi um dos fatores influenciadores para os produtores a optarem pela produção agroecológica, pois diante de fatos relacionados a danos ambientais, não poderiam deixar passar despercebido os riscos que a população corre com a poluição do solo, das águas e principalmente ao elevado aumento do aquecimento global.

Outra motivação estava relacionada com a saúde pessoal e da família, predispondo-se a abandonar o modo convencional de produção, para obter produtos mais saudáveis para o consumo, podendo inclusive, comercializar alimentos de melhor qualidade para população. Por fim, os produtores locais acreditavam que através da produção agroecológica estariam associando informações que contribuiriam para a criação de uma nova marca no mercado "o frango agroecológico". O grupo almejava possuir vantagem competitiva por se tratar de um produto que traria um diferencial entre os demais já comercializados na região.

\section{DISCUSSÃO}

Baseada nos pressupostos de Sarker, Itohara e Hoque (2009), a pesquisa apontou que os agricultores percebem que os sistemas do cultivo agroecológico lhes permitiriam melhoria da renda (nova marca), segurança dos alimentos e redução da poluição ambiental. Após sensibilização durante as reuniões mensais, o grupo dos dez produtores decidiu mudar o modo de produção convencional que vinham praticando para o novo modo aos moldes da agroecologia.

No contexto de produção convencional agrícola de grande escala o fim maior é o econômico, onde incitados pelo uso de novos maquinários, os produtores substituíram a mão de obra pela tecnologia, utilizando tratores, para dobrar a produção em menor tempo e menos trabalho braçal.

A agricultura convencional é o inverso da agroecológica, a primeira visa o elevado uso de insumos agrícolas, apostando em uma produção rápida e em grande quantidade sem ter a consciência dos danos causados, objetivando apenas lucro. Já a agricultura agroecológica aposta em um modelo de produção que 
preserva o solo das contaminações causadas pelos insumos agrícolas, alimentos mais saudáveis, pela não utilização de agrotóxicos, com a expectativa de sustentabilidade.

Por outro lado, (Caporal e Costabeber, 2002, p.16) afirmam a agroecologia orienta o correto redesenho e o adequado manejo de agroecossistemas, na perspectiva da sustentabilidade. Complementando, Moreira e Carmo (2004, p.38) dizem que a agroecologia vai além da questão técnica na agricultura, pois traz reflexões fundamentais para a transformação das Ciências Agrárias e para o redirecionamento da co-evolução entre sociedade e natureza.

No entanto, para que a produção agroecológica torne a propriedade rural familiar sustentável, o processo de transição precisa ser planejado levando em consideração as dimensões sociais, econômicas e ambientais. Nesse trabalho a ênfase foi dada apenas na dimensão social, buscando conhecer as mudanças de atitudes dos produtores rurais familiares e os desafios a serem superados para a produção agroecológica.

Segundo Demori (2012) na perspectiva as formas alternativas de produção agrícola, especificamente a agroecologia, associam-se a alguns elementos essenciais para a sustentabilidade tais como: a preocupação ecológica-ambiental, a estrutura social agrária com base na unidade familiar e o trabalho agrícola direcionado ao associativismo e ao cooperativismo, a identidade cultural e territorial, as relações de reciprocidade e solidariedade dentre outras preocupações em prol do desenvolvimento sustentável (DEMORI, 2012).

Já Reynaud (1983) citado por Wautier (2001) elenca que as pessoas ganham em concretizar seus interesses individuais de trabalho em condições mais flexíveis, no sentido da realização pessoal e de vantagens próprias, através da influência de adesão do trabalho no êxito da ação coletiva. Dessa forma, os produtores rurais familiares da comunidade Vale do Sol I, acreditavam que o trabalho coletivo era uma alternativa de conquistar não somente o mercado, mas sanar os objetivos pessoais, por isso optaram pelo trabalho em grupo.

Meister (1972) citado por Wautier (2001) conceitua o termo "associação" como um agrupamento baseado no recrutamento voluntário e no compartilhamento pelos membros de seus conhecimentos ou de suas atividades com uma finalidade diferente daquela da distribuição dos lucros. A proposta de orientação do NUPES é compatível com a definição supra, uma vez que orientava os produtores na organização do trabalho associativo.

Quanto ao manejo ecológico de acordo com Primavesi (2008) se refere aos princípios naturais, que envolve os seres vivos, o solo, clima e as relações entre si, alterando o menos possível o ambiente, e aproveitando o potencial natural da propriedade, onde a riqueza natural garante a vida para as gerações futuras.

Em busca do manejo natural, os profissionais da SEAPA apresentaram um modelo integrado de produção que estava em fase experimental no município. Tal modelo estava estruturado aos moldes do projeto PAIS do SEBRAE Nacional e forma de mandala, conforme ilustração figura 1.

Scherwisnski (2011) apresenta que a ideia do projeto em forma de MANDALA surgiu de um estudo anterior ao do SEBRAE nacional, que visava proporcionar uma melhor qualidade de vida aos pequenos produtores da agricultura familiar, com o objetivo em atender as necessidades alimentares e gerar renda. $O$ 
programa tem a base de uma lavoura diversificada e irrigada o ano todo; tornando possível cultivar hortaliças, frutas e criação de animais em uma pequena área.

A estrutura de funcionamento do sistema de cultivo tipo mandala é organizada como descrita por Scherwisnski (2011, p. 2), onde "no centro tem-se água, e logo em seguida nove anéis produtivos, inspirados no sistema solar", sendo possível produzir qualquer tipo de alimento, tendo os seguintes objetivos: facilitar a produção de alimentos de forma sustentável; manter a família num espaço pequeno com uma rentabilidade condicional; produzir de forma ordenada sustentável; redução no custo de produção; facilidade no manejo.

\section{CONCLUSÕES}

O estudo apresentado teve como objetivo identificar os desafios a serem superados pelos produtores da comunidade rural Vale do Sol I em prol da produção agroecológica. Os produtores demonstraram abandono pela tendência do individualismo, deixando as diferenças pessoais que comumente afetam o coletivo. Por isso mesmo com os desafios identificados (dificuldades para a utilização da água e acesso a créditos, ausência do documento da terra) conclui-se ser possível aos pequenos produtores rurais produzir de forma integrada e sustentável (PAS). No entanto é necessário que sejam feitas as adequações recomendadas nas propriedades e que o trabalho coletivo seja formalizado em associação ou cooperativa.

Como pesquisas futuras sugere-se que sejam realizadas outras na mesma comunidade a fim de verificar as adequações ocorridas nas propriedades bem como a aceitação do mercado local para o consumo de produtos agroecológico.

\section{REFERÊNCIAS}

AMARAL, J. J. F.. Como fazer uma pesquisa bibliográfica. 2016.

ANDRADES, T. O.; GANIMI, R. N.. Revolução verde e a apropriação capitalista. CES Revista. Juíz de Fora; v.21, n.7, 2007.

BUAINAIN, A. M.. Agricultura familiar, agroecológica e desenvolvimento sustentável: Questões para debate. CA, São Luís, v.5, n.1, p.1-135, 2006.

CAPORAL, F. R; COSTABEBER, J. A.. Agroecologia e Desenvolvimento Rural Sustentável: perspectivas para uma nova extensão rural. Emater. Porto Alegre; v.1, n.1, jan. 2000.

CAPORAL, F. R; COSTABEBER, J. A.. Agroecologia. Enfoque científico e estratégico. Agroecologia e Desenvolvimento Rural Sustentável. Porto Alegre; v.3, n.2, 2002.

CAPORAL, F. R; COSTABEBER, J. A.. Agroecologia: alguns conceitos e princípios. 2016.

COSTA, R. M.; LIMA, A. F. Produção na agricultura familiar: Trajetórias de vida de um grupo de "mulheres" da comunidade vale do sol II, Tangará da Serra - MT. Sober, Vitória, v.1, n.1, 2012.

DEMORI, R. S. L.. Sustentabilidade agroecológica entre agricultores familiares assentados: um estudo de caso no assentamento Zumbi do Palmares, Itapura - SP. Sober, Vitória, v.1, n.1, 2012.

DUARTE, R.. Pesquisa Qualitativa: reflexões sobre o trabalho de campo. Rio de Janeiro: 2002.

FARIA, C. A.. Merkatus: ajudando nossos clientes a atrair clientes. 2016

FILHO, H. M. S.; BATALHA, M. O.. Gestão Integrada da Agricultura Familiar. São Carlos: UFSCAR, 2005.

FINATTO, R. A; SALAMONI, G.. Agricultura Familiar e Agroecologia: perfil da produção de base agroecológica do minicípio de Pelotas/RS. Sociedade \& Natureza, Uberlândia, v.20, n.2, 2008

GIL, C. A.. Como elaborar projetos de pesquisa. 4 ed. São Paulo: Atlas, 2009

GIL, C. A.. Gestão Integrada da Agricultura. 4 ed. São Paulo: Atlas, 2002 
GLIESSMAN, S. R.. Agroecologia: processos ecológicos em agricultura sustentável. 2 ed. Porto Alegre: UFRGS, 2001.

IBGE. Censo Agropecuário 2010. Rio de Janeiro: IBGE, 2010.

KHATOUNIAN, C. A.. A reconstrução ecológica da agricultura. 4 ed. Botucatu: Livraria e Editora Agroecológica, 2001.

KORYTOWSKI, I.; RODRIGUES, A. B.. O Ambientalista Cético: medindo o verdadeiro estado do mundo. 4 ed. Rio de Janeiro: Elsevier, 2002.

MACHADO, F.; CORAZZA, R.. Desafios tecnológicos, organizacionais e financeiros da agricultura orgânica no Brasil. Aportes, Puebla, v.9, n.26, ago. 2004.

MANFREDINI, C. J.. A Vantagem Competitiva como instrumento para conquista da liderança do mercado de escolas técnicas de 20 grau na região do vale do Paraíba: um estudo de caso. Dissertação (Mestrado em Economia) Universidade de Taubaté, Taubaté, 2009.

MELLO, A.; HEMP, S.. Agroecologia. In: SEMINÁRIO ESTADUAL DE AGROECOLOGIA, 6. Anais. Chapecó: 2001.

MOREIRA, R. M.; CARMO, M. S.. Agroecologia na construção do desenvolvimento rural sustentável. Transição

Agroecológica. São Paulo, v.51, n.2, 2004.

MOTA, L.. Projeto de produção agroecológica é lançado pelo SEBRAE Mato Grosso. 2016.

NASCIMENTO, L. F.; LEMOS, Â. D. C.; MELLO, M. C. A. Gestão Socioambiental Estratégica. Porto Alegre: Bookman, 2008.

NETO, F. G.. Questão Agrária e Ecologia: crítica da moderna agricultura. São Paulo: Brasiliense, 1988.

PRIMAVESI, A. M. Agroecologia e Manejo do Solo. 2016.

REGO, J.. Economia Brasileira. 2 ed. São Paulo: Saraiva, 2003.
SARKER, M. A.; ITOHARA, Y.; HOQUE, M.. Determinants of adoption decisions: The case of organic farming. Extension Farming Systems Journal, Bangladesh, v.5, n.2, p.39-46, 2009.

SEBRAE. Inovação no campo, pequenos negócios rurais apostam na diferenciação para ampliar competitividade. Revista n.8, abril, 2008.

SCHERWINSKI, L. K.. Análise de Oportunidade de Negócios estudo de caso da implantação do programa Mandala na escola agrícola municipal Ulisses Guimarães Tangará da Serra-MT. Revista Unemat, Tangará da Serra, v.1, n.1, p.118, 2012.

SCHNEIDER, S.. Teoria social, agricultura familiar e pluriatividade. Revista brasileira de ciências sociais. Santa Catarina, v.18, n.51, 2003.

SILVA, D. B.; CALEMAN, S. M. Q.. Sustentabilidade, Agricultura Familiar e Coordenação: o caso do projeto produção agroecológica integrada e sustentável em Campo Grande/MS - SOBER. 2016

SOUZA, Â. R. L.; MACHADO, J. A. D.; DALCIN, D.. Variáveis que influenciam a tomada de decisão do agricultor pela produção orgânica - SOBER. 2016.

SOUZA, J. C.. Pequena história sobre agroecologia. 2010

SOUZA, N. J.. Desenvolvimento Econômico. 5 ed. São Paulo: Atlas, 2005

TEODORO, P. A. V. B.. Agricultura familiar: uma alternativa para o desenvolvimento sustentável. Unioeste, Cascavel, v.1, n.1, 2005.

TOSCANO, L. F.. Agricultura familiar e seu grande desafio. São Paulo: UNESP, 2016.

WAUTIER, A. M.. A construção identitária e o trabalho nas organizações associativas. Unijuí: 2001. 